failed in the last years before her death in 2004, he devoted his life to her care and comfort, subordinating everything else to making her life as good as it could be. He is survived by their son Jon.

Aage Clausen was an accomplished political scientist. More important, he was a good and kind man who made the lives of people around him better. He is missed a great deal by the people who knew and loved him.

Lawrence Baum, Ohio State University Herbert Weisberg, Ohio State University Elliot Slotnick, Ohio State University

\section{George Rabinowitz}

$\mathrm{T}$ he political science discipline lost one of its sharpest intellects and many of us lost a cherished dear friend when George Rabinowitz passed away, on March 18, 2011. George's death was entirely unexpected. He suffered a sudden cardiac arrest in Trondheim, Norway, where he was on leave from the University of North Carolina, Chapel Hill with a research fellowship.

George Burt Rabinowitz was born on April 27, 1943 in New York City. He was the second son for his parents, Dr. Samuel J. Rabinowitz and Mrs. Rose Rabinowitz. George spent his childhood in the Bronx and he received his undergraduate education at Hobart College in upstate New York. After considering a career in medicine, George went on to graduate school at the University of Michigan. There, he earned an MA in Mathematics in 1971 and a PhD in Political Science in 1973.

Michigan was a particularly exciting place for political scientists in the late 196os and George took full advantage of this stimulating environment. He worked with such giants as Philip Converse (who Chaired George's dissertation committee), Clyde Coombs, and Donald Stokes. George was a very prominent member of the large, interdisciplinary community of graduate students who were affiliated with the Institute for Social Research during this period, many of whom have gone on to become highly visible and influential social scientists on their own. One fellow student, in particular, played an especially important role in George's life: Stuart Elaine Macdonald was also enrolled in the political science $\mathrm{PhD}$ program at Michigan; she and George were married in 1970 . They maintained not only a loving personal relationship but also a highly successful professional collaboration throughout all of the ensuing years.

George spent his academic career in the Department of Political Science at the University of North Carolina. He arrived in Chapel Hill as an instructor in 1971 and advanced steadily through the ranks from assistant professor (1973-1978), through associate professor (1978-1986), to full Professor (1986-2002). In 2002, he was named Burton Craige Distinguished Professor, a title he held until his passing. In addition to his positions at $\mathrm{UNC}$, George was also an influential instructor during the early years of the Inter-University Consortium for Political and Social Research (ICPSR) Summer Program in Quantitative Methods of Social Research where he developed a unique methodological workshop on "Dimensional Analysis."

George's broad scholarly interests touched on all things political. He produced work in a variety of different subfields, including international relations and political socialization. But his main concentrations were quantitative methodology, political behavior and electoral systems. While much of his research, particularly the early efforts, focused on American politics, George eventually developed a strong reputation as a comparativist who made important contributions to scholarly understandings of party systems in western democracies.

Throughout all of his work, George insisted on imposing the highest possible standards in establishing theoretical foundations, carrying out empirical analyses, and developing substantive interpretations. Typically, his research projects would begin with some interesting observation about the political world. The next step would be to develop a formal representation of the subject matter. And, this would be followed by extensive empirical testing. The end result invariably would be new insights that shed important light on the problem that generated the project in the first place and suggested useful avenues for further work. George's entire career embodied the relentless pursuit of powerful theory- even though following this course of action sometimes produced results that raised questions about his own earlier findings. As a direct result of this strict adherence to a regimen of scientific rigor, George's overall set of publications comprises a record of scholarship that resounds with impeccable quality.

Turning to specific lines of research, some of George's earliest scholarly work focused on scaling methods in general, and multidimensional scaling (MDS) in particular, as a strategy for estimating spatial models of electoral competition. This methodology uses information about the "proximities" among a set of objects (e.g., the similarities between a set of presidential candidates) to produce a spatial map in which those objects are shown as points within a dimensional space. Objects that are substantively proximal to each other are represented by points that lie close to each other within the space; objects that are less proximal (or more dissimilar) are shown as points that are farther apart within the space. The general idea is that the resultant configuration of points provides useful evidence about the substantive characteristics that differentiate the objects.

George always emphasized the importance of MDS and related methods as strategies for testing theory, rather than mere tools for exploring multivariate data. In fact, one of his most important contributions was to create a theoretically-consistent dissimilarity measure that could be used to create the proximities data that would serve as input to an MDS analysis. His "line-of-sight," or LOS, measure provides a very useful tool for converting rating scale responses into a matrix of perceptual dissimilarities. The LOS methodology has several demonstrable advantages over the more commonly used ad hoc strategies for assessing interobject dissimilarity (e.g., correlation coefficients, profile distances, etc.). And, the theoretical basis of LOS allows for the placement of the individuals who generated the original rating scales within the space that contains the MDS configuration of stimulus points. Thus, an LOS-based approach facilitates the estimation of the external unfolding model, a geometric construction that has general utility for representing preference data. George's work on MDS is widely recognized, and it continues to be cited in the research literature across a variety of different academic disciplines.

In a second line of work, George examined the effect of personal issue salience as a moderating factor in models of candidate evaluation and issue voting. Among mass political behavior 
researchers, there is something of a bifurcated view on this point: Some contend that feelings of personal importance are a critical factor that effectively divides the general electorate into a set of distinct issue publics, each of which is populated by citizens particularly concerned with a single issue. Others argue that subjective issue salience does not play much of a role in determining how public policy concerns impinge on individual political orientations. There does not seem to be a consensus in favor of one or the other of these contradictory positions; it is certainly the case that studies based on both arguments (i.e., including or ignoring personal issue salience) continue to appear in the literature.

George's main contributions were to show that the effects of personal importance can only be evaluated within the context of the current electoral environment, and that these effects need to be estimated empirically, rather than specified a priori. That is, any given issue has a certain level of "social importance" within an electoral campaign, reflecting its overall salience within the political environment. This is a structural characteristic that exists separately from individual judgments. An individual's belief that a certain issue is more or less important can modify the degree to which that issue enters his or her political evaluations. But, this subjectivity is of limited magnitude: It cannot eliminate the impact of an issue that dominates political discourse during a presidential campaign and it does not elevate idiosyncratic policy concerns (i.e., that are not receiving any attention from elite political actors) to overwhelming importance within a person's decision and evaluation calculus. Nevertheless, personal issue importance does have significant effects that can generate important variability from one person to the next in the impact of particular issues on subsequent political judgments. It is a factor that needs to be taken into account if we are to achieve any sort of detailed understanding about the policy-based reasoning of ordinary citizens.

A third research project focused on the structural characteristics of American electoral politics. George and his colleagues argued that structure-defined as ongoing policy-based dimensions separating contenders in elections-is critical to achieving representation of mass interests and popular control of public policy. Beginning with an individual-level model of voting behavior, but using the states as analytic units, they demonstrated that there is, in fact, a clear coherence to the American political system that provided stability and continuity throughout much of the twentieth century. At the same time, however, the components of the ongoing structure change over time. These changes are usually very small from one election to the next. But they show consistency in directions over time and thereby provide useful information about partisan realignment and the general evolution of the political system.

The initial entry in this series of studies, carried out with Stuart Macdonald and Paul-Henri Gurian, examined the structure of presidential elections. They showed that contests for the presidency are shaped by a combination of party and ideology. And, over the period from the 1940s through 1980, the impact of party decreased while that of ideology increased. Again, the shift in these factors occurred rather slowly, suggesting that electoral change corresponds to an ongoing process of secular realignment rather than to one in which periods of stability are punctuated by discrete "critical" elections.

George and Stuart turned next to a direct consideration of the states' roles in presidential outcomes and, specifically, to their power in determining outcomes. Traditional game theoretic approaches to this problem focused strictly on state size and the resultant variability in Electoral College votes. They showed that the underlying partisan and ideological structure of American elections imposes further constraints on the probability that any specific state will have the ability to cast the deciding vote in any given presidential contest. This finding, in turn, implies that there are enormous disparities in the power of individual voters across different states. Such results raise serious questions about equity and fairness in the degree of representation that exists within the electoral system.This project culminated in a fully articulated theory of structural realignment. Here, the general idea is that political disagreements occur within an existing ideological context that can be conceptualized as an equilibrium state. But, at certain time points, new issues are introduced that lead to disequilibrium and serious modifications to the existing coalitions of political elites. These changes filter through presidential politics down to the general electorate. Stuart and George use an elegant spatial model to show change occurs systematically and that it appears first in movements of congressional voting alignments, followed by changes in presidential voting outcomes, and finally new patterns of mass partisan loyalties. This structural theory of realignment provides a powerful explanation for the co-occurrence of partisan dealignment and the magnified importance of issues which seemed to characterize electoral politics in the mid-twentieth century (and, more speculatively, at other times in American political history). It also shows that, despite the seeming volatility of individual elections, there is actually a great deal of stability and coherence to the American political system.

George Rabinowitz's name is probably most closely associated with the directional theory of issue voting, which was developed with Stuart Macdonald and Ola Listhaug. This innovative perspective on the ways that citizens incorporate policy issues into their electoral decision-making was initially motivated by the fact that empirical political reality is glaringly inconsistent with the predictions of traditional spatial voting models. The latter are based upon "proximity" considerations such that individuals will support parties and candidates whose policies are closest to their own positions. But, George and his colleagues demonstrated that citizens' candidate evaluations do not conform to the singlepeaked functions that are implied by proximity theory. They also showed that parties and candidates do not converge toward the center, which is where rational actors should move, according to proximity theory, in order to position themselves closest to the largest number of voters (who are located near the center of the space within which the parties and candidates compete against each other).

To account for such seemingly anomalous findings, directional theory proposes that citizens have diffuse feelings about policy, characterized by direction (i.e., more or less governmental activity in some program area) and intensity (i.e., mild or strong feelings about the general course of action that is preferred), rather than specific stands on issues that are preferred over alternative positions in any other direction. This view is fully consistent with the low levels of sophistication that pervade most electorates. And it also is completely appropriate, given the symbolic nature and valence characteristics of many prominent issues.

Empirical predictions based upon directional theory stand in direct contrast to those derived from proximity-based spatial 
models. At the mass level, individuals should support candidates and parties that take the most pronounced positions in their preferred direction of public policy-so long as they are not extremists. This, in turn, implies monotonic, rather than singlepeaked preference functions relating individual issue positions to candidate/party support. At the elite level, directional theory suggests that political actors have no motivation to move toward the center. Instead, they should stake out relatively extreme positions-once again, without crossing the limits of acceptability- to attract support from voters whose diffuse feelings about issues lead in the same direction.

Stated simply, the hypotheses generated from directional theory are supported strongly by the empirical evidence. The theory was originally tested in the American two-party context. George and his collaborators immediately extended it to the multiparty systems that more frequently characterize western democratic systems. And, in virtually every case, mass preferences and elite positions conform much more closely to the realities of a directional world, rather than those implied by a proximity-based system.

As might be expected, there has not been uniform acceptance of the superiority of the directional theory over proximity theory. To the contrary, there have been a number of critiques that have asserted the superiority of the proximity model on several different grounds. But, George and his colleagues have responded to the objections that have been raised against their work in ways that not only address the specific criticisms but also strengthen and extend the directional theory, itself. While it is probably too much to say that directional theory has supplanted proximitybased spatial models, it does provide a new, provocative, and productive way to think about the interactions between the mass public and elite political actors. It certainly will have a profound influence on the study of electoral systems well into the future.

It is important to point out that the preceding division of George Rabinowitz's work into four distinct areas is somewhat artificial. In fact, George's different research activities complemented and contributed to each other very nicely. For example, the foundations of directional theory emerged from empirical observations in the work on multidimensional scaling models. Similarly, George's interest in scaling models is reflected very clearly in the innovative factor representations of American elections that appear in the work on structural realignment. Going further, the latter project helped to define the leadership role that political elites play relative to their mass-level supporters in the directional model of partisan competition. And, the application of directional theory to issue voting models also helps to clarify the mediating role of personal importance. Thus, George Rabinowitz's varied research activities definitely were not characterized by works that addressed different "targets of opportunity." Instead, his life as a scholar is clearly manifested in a strong and coherent research program that made important progress on several different theoretically prominent fronts.

George's scholarly accomplishments were recognized in a number of ways. Along with Stuart Macdonald and Ola Listhaug, he received the ${ }_{1989}$ Franklin L. Burnette-Pi Sigma Alpha Prize for the Best Paper presented at the 1988 Annual Meetings of the American Political Science Association. This same group also received the 1992 Heinz Eulau Prize for the best paper published in the American Political Science Review during 1991. And in 2003 , George was elected to membership in the Norwegian
Society of Science and Letters. Thus, George's work was acknowledged and celebrated by the academic community.Turning to his role as a teacher, George Rabinowitz had a profound impact on several generations of political science graduate students at UNC. For one thing, he was a wonderful instructor. His seminars on electoral behavior and dimensional analysis, in particular, were unique experiences that had life-changing effects on many of their participants. More generally, George was a great advisor and mentor, widely recognized for being supportive and helpful. He was always willing to listen patiently while eager students spouted brilliant new ideas intended to solve all of the most pressing theoretical problems in political science. His patience during such sessions was legendary. But, George was not just a passive sounding board; to the contrary, he always provided highquality responses. He possessed a wonderful ability to help others Atranslate general ideas into workable research problems. And, probably more important, he was adept at offering criticism that was incisive, but always constructive. George set very high standards. But he was such a positive force that he motivated many graduate students into striving to similar levels of quality in their own work. The tangible result from George Rabinowitz's presence in the UNC political science $\mathrm{PhD}$ program was the nearly continuous stream of young scholars who emerged from Chapel Hill over the course of four decades and went on to highly successful careers of their own. UNC recognized George's contributions to graduate training by presenting him the 1997 Charles Robson Award for Excellence in Graduate Instruction.

George was also an excellent instructor at the undergraduate level. He taught a range of courses over the years, but certainly received his greatest exposure in the large introductory sections of American Government. George $=$ s informal style and enthusiasm about the material he taught endeared him to his students. And, amazingly, he achieved this great rapport without either "dumbing down" the information or compromising his rigorous standards for evaluation. So, here too, George Rabinowitz had a definite positive effect on the people who passed through his classrooms.

Looking beyond academic activities and scholarly accomplishments, George was a wonderful human being. He possessed a warm friendliness, a great sense of humor, and a genuine orientation of caring for others. George's personality had a positive effect on everyone who interacted with him. This had far-reaching consequences: Over the years, the UNC Political Science Department has been known for its collegial, indeed almost familial, atmosphere. And much of this was due to George's presence and active participation in its social activities.

Outside the office, George loved cooking, playing golf, going to movies, plays, and concerts, and getting together with friends. He was also strongly devoted to his family. During recent years, George was the primary care-giver for his elderly parents, who had moved to an assisted living facility in Chapel Hill. He was intensely proud of his sons, Joshua, now an MD and professor of chemistry and integrative genomics at Princeton, and David, a teacher, writer, and filmmaker who is currently in the MBA program at the Massachusetts Institute of Technology. And, he felt great joy when his daughter-in-law, Emily (Joshua's wife, an associate professor of psychology at Princeton), gave birth to his first grandson, James. Of course, George's greatest collaboration-in all ways-- was with his wife, Stuart. For 41 years, they demonstrated that it is possible to combine personal and professional 
life in immensely rewarding and highly successful ways. George and Stuart were wonderful together and their relationship continues to serve as a fantastic role model for other couples throughout the discipline.

George Rabinowitz's passing leaves a terrible void in the lives of all those who benefitted from his friendship, wisdom, and kindness. We will miss him very deeply. But, George's memory will also live on in his family, his many friends and colleagues, and his important contributions to scholarship.

Those who wish to honor George's life and scholarship should consider making a contribution to the George Rabinowitz Memorial Fund in Political Science, The Arts and Sciences Foundation, ATTN: Ali Kroeger, 134 East Franklin Street, Chapel Hill, NC 27514.

William G. Jacoby, Michigan State University

\section{Robert E. Hawkinson}

$\mathrm{R}$ obert E. Hawkinson died May 22, 2011 of an apparent heart attack at the age of 68. At the time of his death Prof. Hawkinson was Emeritus Dean of Campus Life/Associate Professor of Politics at Willamette University in Salem, Oregon. He was also Kaneko Faculty Commons Mentor, a position created as part of the Residential Commons system initiated by Prof. Hawkinson during his tenure as Campus Life Dean at Willamette. During his nearly thirty years at Willamette, Bob Hawkinson was a fixture on campus and one of the most revered educators, advisors, and mentors, reaching out to generations of students through his inspired teaching and committed dedication to the intellectual life of the university community. Although Bob was rewarded with emeritus status in 2009, he continued to teach in the Politics Department at Willamette for the remaining two years of his life.

Bob Hawkinson was raised in Chicago. He graduated from Swarthmore College in 1966 where he majored in political science and then returned to his home town where he enrolled in graduate school at the University of Chicago. Bob earned his MA and $\mathrm{PhD}$ in political science in 1969 and 1977, respectively. His dissertation, "Presidential Program Formulation in Education:Lyndon Johnson and the 89th Congress," was informed in part by his work as a research assistant at the Brookings Institution and a junior staff associate at the National Opinion Research Center in Chicago. Bob's dissertation also blended his lifelong interests in American government and public policy focused on education. Over the course of his career Bob's devotion to the promotion of excellence in higher education never wavered.

Bob's vocation as a classroom educator began before the completion of his doctoral thesis. While pursuing his $\mathrm{PhD}$ he held teaching positions at the University of Chicago and the University of Alabama at Birmingham. Bob taught as an Assistant Professor at the University of California at Santa Cruz full time from 1973 to 1982 at which time he joined the faculty in the Politics Department at Willamette University. In 1986 Bob was promoted to Associate Professor at Willamette. Bob's service to Willamette extended to his administrative positions. He served as Associate Dean of the College of Liberal Arts from 1993 to 1996 and did yeoman's work shepherding the college's new general educa- tion requirements through the process of proposal, debate, and approval, no small feat given the central role of general education to the undergraduate curriculum at Willamette. In 1998 Bob was named Interim Vice President for Student Affairs and later served as Dean of Campus Life prior to his retirement from fulltime service.

Among Bob's greatest accomplishments was the creation of a residential commons program at Willamette. Bob believed that students benefitted best from immersion in a collegiate academic experience. He lived that creed, seeking out advising roles on campus and serving as a mentor to countless students and student organizations. Bob was integral to the development of the World Views and College Colloquium freshman seminar series that have been signature elements of the undergraduate curriculum at Willamette. Bob's own courses in the Politics Department, including American Political Thought and American Political Organizations, reflected his ability to synthesize concepts in American government and political theory in ways that were both challenging yet accessible to the undergraduate students. Bob's courses were highly sought out by Willamette undergraduates who praised Bob's teaching in superlatives unmatched by most of his colleagues.

As a researcher and author Bob was a keen scholar of American political life. In numerous publications and conference papers Bob explored the meeting points between political ideology and public policy. In his later works Bob's attention turned to local politics in Oregon, a topic in which he developed a deep interest. Bob's knowledge of American national and local politics and government was encyclopedic. He seemingly knew about every aspect of political structures and institutions in the United States and could best just about any challenger in a game of American political trivia. Over the course of his career Bob was the recipient of numerous grants and fellowships including the Woodrow Wilson Fellowship, the Morton Grodzins Public Policy Fellowship, and fellowships at the National Institutes of Mental Health and the Lyndon Baines Johnson Library.

Bob was a cherished colleague. His wit and humor were a strong tonic to quotidian tasks in the modern academy. When former Oregon Senator Mark Hatfield came to Willamette to teach briefly following his retirement from the Senate, Bob mischievously scoured Willamette's archives to find course catalogs from the years when the senator had taught in what was then known as the Politics Science Department (Hatfield also preceded Bob by several decades as Dean of Students at Willamette). With a twinkle in his eye, Bob suggested to Hatfield that he resurrect his course offerings from the 1950s, the topics of which were quaintly dated. One of Bob's last acts was to attend Willamette commencement one week to the day before his death. It was fitting that Bob was present at graduation exercises to see off yet one more class of students on whom he had a profound impact. Bob's vocation and avocation alike were the same, as an educator of political science. He truly embodied Willamette's motto, Non nobis solum nati sumus, "Not unto ourselves alone are we born."

Bob was the only son of Ervil and Elizabeth Hawkinson and is survived by his first cousins, Sara Meyers, Constance Miller, Ann Kone, Reeve C. Parker, Elizabeth Parker, and their children and grandchildren. 